\title{
Skin Non-Melanoma and Rare Malignancies of Head and Neck in Uttarakhand: A 2-Year Experience at a Tertiary Centre of Northern India.
}

\author{
Dr.Navneet Jain ${ }^{1}$, Dr.Neena Chauhan ${ }^{2}$, Dr.Priyank Pathak ${ }^{3}$, Dr.Sunil Saini ${ }^{4}$ \\ ${ }^{I}$ Dr.Navneet Jain M.S,Assistant Professor, Department Of Surgical Oncology,Swami Ram Himalayan \\ University, Dehradunuttrakhand India. \\ ${ }^{2}$ Dr.Neenachauhan M.D, Professor,Department Of Pathologyswami Ram Himalayan \\ University, Dehradunuttrakhand India. \\ ${ }^{3}$ Dr.Priyankpathak M.S, Resident,Department Of Surgery,Swami Ram Himalayan \\ University, Dehradunuttrakhand India. \\ ${ }^{4}$ Dr. Sunil Saini M.S, Professor, Department Of Surgical Oncology,Swami Ram Himalayan \\ University,Dehradunuttrakhand India.
}

\begin{abstract}
:
Introduction: Non-Melanotic skin cancers (NMSC) is an infrequent entity in the Indian subcontinent as compared to western population. Existing literature on NMSCs in India is limited mostly to case reports and few reviews only. This article describes the clinical and pathological profile of patients presenting with NMSC and other rare malignancies of head and neck at a tertiary Centre in Northern India.

Material and method: A retrospective study of 27 cases of common skin cancers and 5 rare cases received at a tertiary cancer hospital in Uttrakhandbetween December 2013 to December 2015. These skin cancer were reviewed and analyzed, based on appropriate history, clinical examination, histopathology and Immunohistochemistry confirmation.

Results: A total of 32 histologically diagnosed skin malignancies including rare cases were analyzed during the period under review in Cancer Research Institute. Basal cell carcinoma(BCC) was the most common skin malignancy consisting of $16(50 \%)$ of cases followed by squamous cell carcinoma(SCC) with $11(34.3 \%)$ cases. 26 cases $(81.2 \%)$ were male and 6 cases $(18.7 \%)$ were female with a male to female ratio of $4: 1$. Age ranged from 10 years to 85 years. Five rare cases including Dermatofibrosarcomaprotuberans(DFSP),Non Hodgkins lymphoma (NHL)Lacrimal gland, low grade sarcoma, Sweat gland carcinoma and xerodermapigmentosa with Carcinoma in situ constituted about $15.6 \%$ with one case each.

Conclusions: Most frequent primary skin cancers were basal cell carcinoma (BCC) followed by squamous cell carcinoma (SCC) and other rare cancers. In our experience skin malignancy of head and neck present early as well as in advanced stage but can be managed successfully with acceptable outcome. For better management similar studies should be encouraged.
\end{abstract}

Keywords: Cutaneous, BCC, SCC, rare malignancies, head and neck

\section{Manuscript}

Introduction: Non-melanoma skin cancers (NMSC) are relatively uncommon in India comprising 1$2 \%$ of all skin cancers. (1) This is predominantly due to protection offered by melanin pigment against ultraviolet radiation induced DNA damage. There is paucity of data regarding exact incidence, risk factors, clinical presentation and prognosis of these cancers from India. Majority of NMSCs are located in head and neck region as these are the most sun exposed regions of the body $(2,3,4)$. NMSCs of head and neck have a wide spectrum ranging from indolent basal cell carcinomas to very aggressive Merkel cell carcinomas. The incidence of $\mathrm{BCC}$ is increasing with wide geographical variations(5) with several histological variants including nodular, pigmented, sclerosing, superficial and basisqumaous.(6,7) This study was undertaken to evaluate the incidence, clinical and pathological profile of head and neck NMSCs presenting to our institute.

Material and methods: The present study was conducted in cancer research institute,Swami Ram Himalayan university,DehradunUttrakhand,India.A total of 32 cases were selected which included 27 cases of cutaneous BCC and SCC. 5 rare cases of other head and neck malignancies were also included in the studyon the basis of their low incidence and limited case reports in the literature,out of which three cases were rare cutaneous malignancies and one case of sarcoma of neck with skin involvement and one case of NHL of lacrimal gland. This retrospective analysis of all such cases received at the Department of Surgical Oncology from Dec 2013 to Dec 2015 was performed. All cases having histopathological proven non melanoma skin 
cancer were included in the study.The clinical data (age, sex, and site) was obtained from hospital case records and histopatholgyslides of the cases under study were reviewed to determine the relative frequency of various skin cancer of head and neck.

Results:

Table-1: Age/Sex distribution of SCC/BCC/Rare cancers in the present study

\begin{tabular}{|l|l|l|l|l|l|l|l|}
\hline & \multicolumn{2}{l}{ SCC } & BCC & \multicolumn{2}{l|}{ Rare cancers } & Total(\%) \\
\hline Age(years) & Male & Female & Male & Female & Male & Female & \\
\hline $10-20$ & 0 & 0 & 0 & 0 & 1 & 0 & 3.12 \\
\hline $21-30$ & 0 & 0 & 0 & 0 & 1 & 0 & 3.12 \\
\hline $31-40$ & 0 & 0 & 1 & 0 & 1 & 0 & 6.25 \\
\hline $41-50$ & 1 & 0 & 2 & 2 & 0 & 0 & 15.6 \\
\hline $51-60$ & 4 & 0 & 3 & 0 & 2 & 0 & 28.1 \\
\hline $61-70$ & 2 & 1 & 4 & 2 & 0 & 0 & 28.1 \\
\hline $71-80$ & 1 & 1 & 2 & 0 & 0 & 0 & 12.5 \\
\hline $81-90$ & 1 & 0 & 0 & 0 & 0 & 0 & 3.12 \\
\hline Total & 9 & 2 & 12 & 4 & 5 & 0 & \\
\hline
\end{tabular}

Table-2: Distribution of Primary sites involved by SCC/BCC/Rare cancers in the present study.

\begin{tabular}{|l|l|l|l|l|l|l|l|l|}
\hline Site Distribution & SCC & BCC & DFSP & NHL & $\begin{array}{l}\text { Low } \\
\text { grade } \\
\text { sarcoma }\end{array}$ & $\begin{array}{l}\text { Sweat gland } \\
\text { carcinoma }\end{array}$ & $\begin{array}{l}\text { XP with } \\
\text { SCC in } \\
\text { situ }\end{array}$ & $\begin{array}{l}\text { Total } \\
(\%)\end{array}$ \\
\hline Upper Lip & 2 & 0 & 0 & 0 & 0 & 0 & 0 & $2(6.25)$ \\
\hline Lower Lip & 3 & 0 & 0 & 0 & 0 & 0 & 0 & $3(9.37)$ \\
\hline Face & 1 & 6 & 0 & 0 & 0 & 0 & 1 & $7(21.8)$ \\
\hline Nose & 3 & 2 & 0 & 0 & 0 & 0 & 0 & $5(15.6)$ \\
\hline Ear(pinna) & 0 & 1 & 0 & 0 & 0 & 0 & 0 & $1(3.12)$ \\
\hline Conjunctiva & 2 & 0 & 0 & 0 & 0 & 0 & 0 & $2(6.25)$ \\
\hline Scalp & 0 & 2 & 1 & 0 & 0 & 1 & 0 & $4(12.5)$ \\
\hline Lateral canthus Eye & 0 & 1 & 0 & 0 & 0 & 0 & 0 & $1(3.12)$ \\
\hline $\begin{array}{l}\text { Lacrimal gland(Left } \\
\text { eye) }\end{array}$ & 0 & 0 & 0 & 1 & 0 & 0 & 0 & $1(3.12)$ \\
\hline Neck(Right side) & 0 & 0 & 0 & & 1 & 0 & 0 & $1(3.12)$ \\
\hline Eyelids & 0 & 4 & 0 & 0 & 0 & 0 & 0 & $4(12.5)$ \\
\hline Total & 11 & 16 & 1 & 1 & 1 & 1 & 1 & 32 \\
\hline
\end{tabular}

(SCC-Squmous cell carcinoma, BCC-Basal cell carcinoma, Rare Cancers: DFSP-

Dermatofibrosarcomaprotuberans, NHL-Non HodgkinsLymphoma,Low grade sarcoma,Sweat gland carcinoma, XP-Xerodermapigmentosawith CA in situ)

[Fig-1]: Histological Grading of SCC Cases in the present study

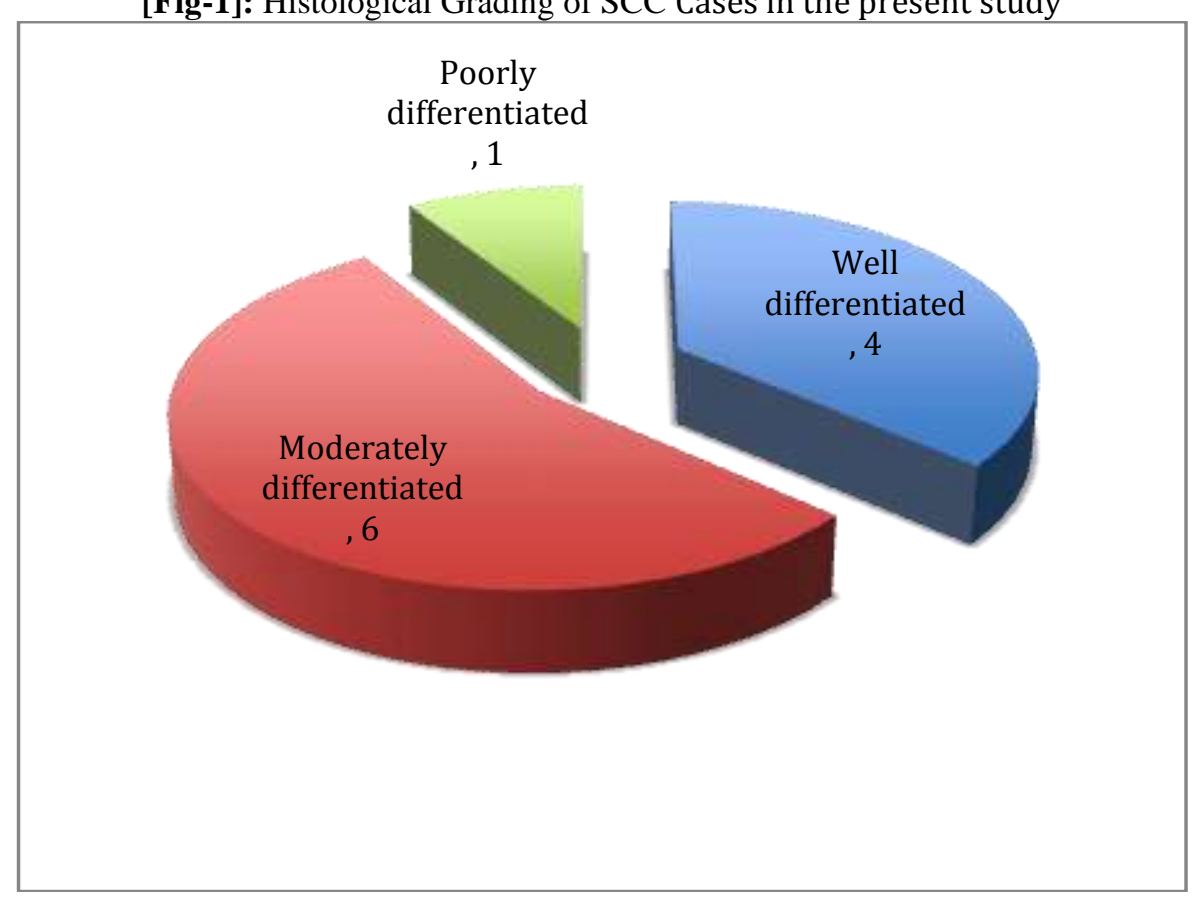


[Fig-2]: Histological Variants of BCC seen in this study.

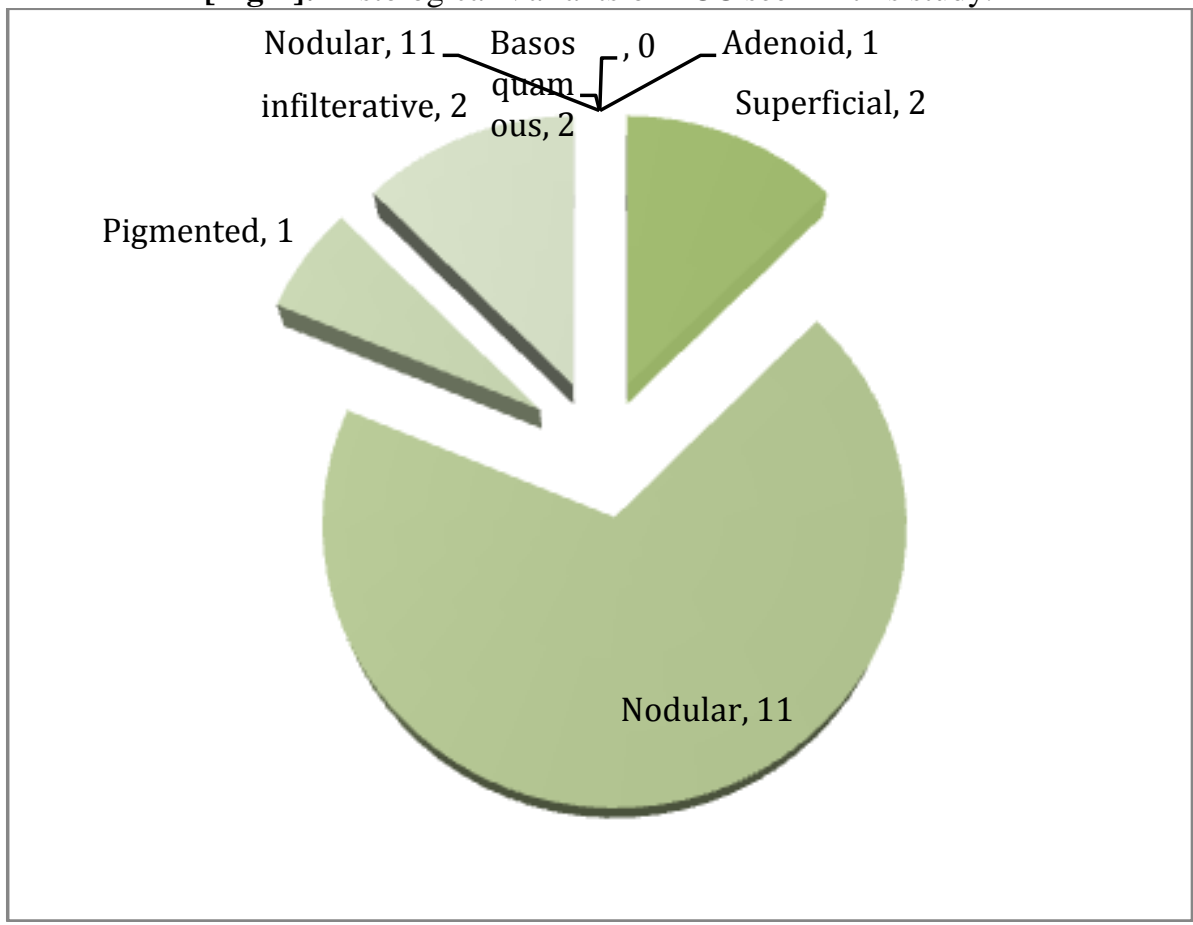

\section{Results}

Of the thirtytwo cases of NMSCs analyzed during the 2 year study period, 16 cases $(50 \%)$ were BCC followed by 11 cases $(34.3 \%)$ of SCC.The ratio of BCC $(n=16)$ to $\operatorname{SCC}(n=11)$ was $1.45: 1$ which signifies that BCC is more common skin malignancy of head and neck in comparison to SCC in present study. Age ranged from 10 till 85 years out of which the most common age group for SCC was 51-60 years and BCC was 61-70 years. The age of patient presented with XP with CA in situ was 10 years, patient of DFSP scalp was 35 years, patient of lacrimal gland NHL was48 years, patient with sweet gland carcinoma was 56 years and patient of Low grade sarcoma neck was 58 years.[Table-1]Distribution of primary sites involved is shown in [Table-2], Of the sixteen cases of BCC, most common involved site were face and eyelids. In case of SCC, of the eleven cases, 3 cases each had involvement of the lips and nose followed by conjunctiva in 2 cases. Out of the 16 cases of BCC, most common histological variant was nodular, seen in 11 out of 16 cases (17).For SCC, the most common histological grade(18)was moderately differentiated with 6 cases and well differentiated in 4 cases and one case of poorly differentiated carcinoma.[Fig-1,2]:

\section{Discussion}

This study provides baseline information about the pattern of NMSC in region of NorthernIndia. Our goal was to study the incidence of skin and other rare cancers of head and neck presented in our centre. BCC has been reported to be most common skin cancer and various studies from India have reported SCC to be most prevalent skin cancer (8) but our studied showed higher incidence of BCC, which is similar to previous studies at various centers (9). BCCs in this study were more common in males as reported in most studies worldwide, presumably due to greater occupational and recreational exposure to ultraviolet radiation (UVR). The higher incidence of BCC in comparison to SCCcould be directly related to the occupation of the patients who were of low socio-economic status and regularly exposed to sunlight.SCC most commonly involves the ear, front temporal region of the scalp and cheek in the head and neck region (10).After analyzing the anatomical site for occurrence of BCC, In our study cheek was the commonest followed by nose. These results are in correlation with those reported by Chow et al. (11) and Aandani and Ganatra(12).In our study, NMSC showed significant male predominance, with male to female ratio being 5:1 and it is similar to the other many studies, which also had male predominance (13). The most common histopathological pattern for SCC was the moderately differentiated form constituting $6 \%$ which is in contrast to study by Alakloby et al. which had well differentiated as the most common (14). The most common histopathological pattern for BCC was the solid (nodular) pattern also reported by Alakloby et al. [8].In this study, xerodermapigmentosa was mainly associated with SCC; nevertheless this inherited disorder is the prototype genodermatosis associated with both SCC and BCC (15).The other tumors rarely seen were, DFSP, NHL and Low grade sarcomaSweat Gland carcinoma and xerodermapigmentosa with SCC in situ.DFSP constitutes less then $0.1 \%$ of all malignant neoplasm with head 
and neck being the least common site of involvement(19),NHL of orbit commonly involves conjunctiva or eyelid but primary NHL of lacrimal glands is relatively rare (20),Adenexal carcinomas of skin are rare tumor both benign and malignant.Adenexal tumor represents 1-2\% of skin cancers(21),Soft tissue sarcomas are uncommon tumors representing less then $1 \%$ of all malignant adult tumors. They are rarer in head and neck and have a average frequency of $5-15 \%$ of all adult sarcomas and less then $1 \%$ of all head and neck neoplasm(22,23),XP is a rare disease with incidence of 1:250.000, 1:50,000 in Japan but the incidence is not well known in India(24).

The most commonly affected age group in our study was 51-70 years (56.2\%) followed by $41-50$ years (15.6\%), 71-80 years (12.5\%), 31-40years (6.25\%) and 81-90 years (3.12\%). The findings are similar to another study conducted in East India (16). Surgery is the mainstay treatment of non-melanoma skin malignancies. Wide surgical excision with adequate margins was performed in all our cases with appropriate reconstruction in single sitting followed by adjuvant radiotherapy in some cases as recommended.

\section{Conclusion}

Basal cell carcinoma represents the highest frequency among all non-melanoma skin cancers of the head and neck region with face and eyelid being the most frequent sites. The majority of BCCs and SCCs arisedenovo without any identifiable risk factors. These cancers are potentially lethal and warrants early treatment and close follow up.

\section{References}

[1]. National cancer registry programme, Indian council of medical research. Consolidated report of the population based cancer registries 1990-96

[2]. Leaf A. Potential health effects of global climatic and environmental changes. N Engl J Med. 1989;321:1577-83.

[3]. M. J. Veness, S. Porceddu, C. E. Palme, and G. J. Mor- gan, "Cutaneous head and neck squamous cell carcinoma metastatic to parotid and cervical lymph nodes," Head \& Neck, vol. 29, no. 7, pp. 621-631, 2007.

[4]. Aandani and A. Ganatra, "Incidence of basal cell carcinoma at plastic surgery department of tertiary care hospital in Karachi," Journal of Surgery Pakistan, vol. 27, pp. 117-120, 2011.

[5]. V. L. Chow, J. Y. Chan, R. C. Chan, J. H. Chung, and W. I. Wei, Basal cell carcinoma of head and neck region in ethnic Chinese.International Journal of Surgical Oncology,2011; vol. 2011:167-178.

[6]. I. Hussain, M. Soni, B. S. Khan, and M. D. Khan, Basal cell carcinoma presentation, histopathological features and correlation with clinical behavior,Pakistan Journal of Oph- thalmology 2011; vol. 27:1-7.

[7]. Marks R. An overview of skin cancers. Incidence and causation. Cancer 1995;75(2 Suppl):607-612

[8]. Deo SV, Sidhartha H, Shukla NK, Kumar S, Kar M, Samaiya A; Surgical management of skin cancers: experience from a regional cancer centre in North India. Ind J Cancer 2005; 42(3): 145-50.

[9]. Crowson AN. Basal cell carcinoma: biology, morphology and clinical implications. Mod Pathol 2006;19:S127-47.

[10]. T. J. Vauterin, M. J. Veness, G. J. Morgan, M. G. Poulsen, and C. J. O’Brien, "Patterns of lymph node spread of cutaneous squamous cell carcinoma of the head and neck," Head \& Neck, vol. 28, no. 9, pp. 785-791, 2006.

[11]. V. L. Chow, J. Y. Chan, R. C. Chan, J. H. Chung, and W. I. Wei, "Basal cell carcinoma of head and neck region in ethnic Chinese," International Journal of Surgical Oncology, vol. 2011, Article ID 890908, 7 pages, 2011.

[12]. A. Aandani and A. Ganatra, "Incidence of basal cell carcinoma at plastic surgery department of tertiary care hospital in Karachi," Journal of Surgery Pakistan, vol. 27, pp. 117-120, 2011.

[13]. Raasch BA, Buettner PG. Multiple non- melanoma skin cancer in an exposed Australian population. J Dermatol2002;41:625-8.

[14]. Alakloby OM, Bukhari IA, Shawarby MA (2008) Histopatholo- gical pattern of non melanoma skin cancers at king fahd hospital of the university in the eastern region of Saudi Arabia during the years 1983-2002. Cancer Ther 6:303-306

[15]. Samarasinghe V, Madan V. Nonmelanoma skin cancer. J CutanAesthetSurg 2012;5:3-10.

[16]. R. S. Laishram, A. Banerjee, P. Punyabati, and L. D. C. Sharma, "Pattern of skin malignancies in Manipur, India: a 5-year histopathological review,” Journal of Pakistan Association of Dermatologists, vol. 20, no. 3, pp. 128-132, 2010.

[17]. LeBoitPE,BurgG,WeedonD,SarasinA,eds.World Health Organization classifications of tumors.Pathology and genetics of Skin Tumors,Lyon:IARC Press 2006: 10-33.

[18]. AJCC6thEdCancerStaging 2002.

[19]. BhavnaChawla MS, SeemaKashyap MD, Sanjay Sharma MD, Mandeep S. Bajaj MD et al Atypical Presentation of Primary NonHodgkinLymphoma of the Lacrimal Gland Del J Ophthalmol 2012;22(4):287-288.

[20]. Jorge O Guerrissi and Juan Pablo Quiroga: Adnexal carcinomas of the head and neck.Indian Journal of plastic surgery 2008; vol 41(2):229-234.

[21]. Snehal G. Patel, MS, FRCS, Ashok R. Shaha, Jatin P. Shah,Soft tissue sarcomas of the head and neck: An update.American journal of otolaryngology 2001; 22:2-18.

[22]. Pandey M, Chandramohan K, Thomas G, Mathew A, Sebastian P, Somanathan T, Abrham EK, Rajan B, Krishnan Nair M (2003). Soft tissue sarcoma of the head and neck in adults. Int J Oral MaxillofacSurg; 32: 43-8.

[23]. Sudhir M. Naik,Ashok M. Shenoy,A. Nanjundappa,RajshekarHalkud,PurshottamChavan,K. Sidappa,

[24]. Sumit Gupta,Cutaneous Malignancies in XerodermaPigmentosum: Earlier Management Improves Survival

[25]. I ndian Journal of Otolaryngology and Head \& Neck Surgery. 2013; 65(2): 162. 